\title{
The effect of pre-operative high doses of methylprednisolone on pain management and convalescence after total hip replacement in elderly: a double-blind randomized study
}

\author{
Artur Gądek $^{1,2} \cdot$ Henryk Liszka ${ }^{2,3}$ (1) $\cdot$ Małgorzata Zając $c^{2,4,5}$ \\ Received: 31 March 2020 / Accepted: 4 September 2020 / Published online: 17 September 2020 \\ (C) The Author(s) 2020
}

\begin{abstract}
Purpose The aim of the study was to assess whether administration of a single dose of methylprednisolone in the group patients above 65 years of age will be effective in complex analgesic management after total hip arthroplasty (THA).

Methods Seventy-seven patients above 65 years old were double-blind randomized into two: the study and controls groups. Preoperatively, the study group received as a single dose of $125 \mathrm{mg}$ intravenous methylprednisolone, while the others saline solution as placebo. Peri-operatively, all the patients were administered opioid and nonopioid analgesic agents. We measured the levels of inflammatory markers (leukocytosis, C-reactive protein - CRP), pain intensity level (visual analog scale_VAS; numerical rating scale-NRS), the life parameters, and noted complications.

Results Following administration of methylprednisolone were significantly lower levels of CRP on all the four post-operative days; leukocytosis on the second day; the VAS/NRS score at rest after six, 12, and 18 hours post-operatively, diminished the dose of parenteral opioid preparations (oxycodone hydrochloride), the duration of analgesia by peripheral nerve block was significantly higher as compared with the placebo group $(p<0.000001)$. No infectious complications were noted; there was one patient who developed post-operative delirium.

Conclusion A single dose of methylprednisolone significantly reduces the level of post-operative pain at rest on the day of THA in the group patients above 65 years of age, decreases the dose of opioid analgesic agents, and significantly decreases the level of inflammatory markers, without infectious processes.
\end{abstract}

Keywords Total hip joint replacement $\cdot$ Methylprednisolone $\cdot$ Opioid dose $\cdot$ Pain intensity $\cdot$ Infection rate

\section{Introduction}

Total hip and knee arthroplasties are associated with considerable pain between the sixth and 24th post-operative hour

Henryk Liszka

henryk.liszka@uj.edu.pl

1 Department of Orthopedics and Physiotherapy, Jagiellonian University Collegium Medicum, Krakow, Poland

2 Department of Orthopedics and Traumatology, University Hospital in Krakow, Krakow, Poland

3 Department of Anatomy, Jagiellonian University Medical College, Krakow, Poland

4 Department of Anaesthesiology and Intensive Care, Jagiellonian University Collegium Medicum, Krakow, Poland

5 Department of Anaesthesiology and Intensive Care, University Hospital in Krakow, Krakow, Poland
[1-3]. The surgical incision, as a mechanical factor, affects the nociceptor, initiates the pain process, and triggers numerous inflammatory mediators [1, 4, 5]. The Enhanced Recovery After Surgery (ERAS) with the method multimodal analgesia accelerates the patient's returning to full activity [4-10] and limits the complications and time of hospitalization [9-14]. Of interest is whether ERAS protocol is effective in the group patients older than 65 years, who more commonly suffer from concomitants diseases and whose comorbidities are more advanced; the physiological functional reserve is decidedly lower due to systemic involution [10-13,15].

The management aiming at reducing the inflammatory process and pain for chronic osteoarthritis is commonly administered intra-articular glucocorticoid injections, hence the interest, whether administration only once, as a "pre-emptive" analgesia, may effectively limit acute pain, will not the immunosuppressive effect resulting among others from blocking the elements of the native immune system, increase the risk of infectious complications 
developing? Numerous reports have indicated an effective use of methylprednisolone as an element of multimodal analgesia in orthopaedic surgery $[1,9,16-21]$.

\section{Objective}

The objective of the study was the effectiveness of methylprednisolone administration in complex peri-operative analgesic therapy in patients above 65 years of age, subjected total hip arthroplasty (THA). The authors attempted to answer the questions whether a one-time administration of methylprednisolone will reduce the following: (1) the pain level in the post-operative period, the value of visual analog scale (VAS), and numerical rating scale (NRS) at rest at every six hours on the day of surgery; (2) the dose of the parenteral analgesic agents, including opioids; (3) the mobilization of inflammatory process parameters; (4) the occurrence of adverse effects that would delay early rehabilitation on the ERAS protocol; (5) maintain a stable glycemia level.

\section{Material and methods}

The analysis included a group of 92 patients above 65 years of age, subjected to elective unilateral THA, performed in keeping with the ERAS protocol in the period from January 1 to June 30, 2019. Fifteen patients were excluded from the study due to clinical situations that limited the use of a glucocorticoid: 1/diabetes type 1 and 2; 2/rheumatoid arthritis; 3/when C-reactive protein (CRP) levels were above normal values $\geq$ $5 \mathrm{mg} / \mathrm{L} ; 4 /$ chronic steroid treatment; $5 /$ peptic ulcers within the past 30 days.

The patients were subjected to the standardized spinal anaesthesia procedure, with subsequent fascia iliaca compartment blockade at the operated side, followed by THA from the lateral approach. Prior to anaesthesia induction, the patients received intravenous agents: an infection-preventing (cephazolin $2.0 \mathrm{~g}$ ), in order to achieve haemostasis (tranexamic acid $1.0 \mathrm{~g}$ ), and an antiemetic control (ondansetron $8 \mathrm{mg}$ ). The fluid intake (crystalloids) was standardized: $12 \mathrm{~mL} / \mathrm{kg} / \mathrm{h}$ in the first hour and $6 \mathrm{~mL} / \mathrm{kg} / \mathrm{h}$ in the following hours of operation, erythrocyte mass was packed, red blood cells were transfused, when blood loss exceeded $600 \mathrm{~mL}$. Pain management was determined on the VAS/ NRS tools at rest every six hours; if the pain score was $\geq 4$ points, oxycodone hydrochloride at the subcutaneous dose of $0.1 \mathrm{mg} / \mathrm{kg}$ of body weight was administered; if the pain score was $2-4$ points, paracetamol and metamizole were calculated for $1 \mathrm{~kg}$ of body weight. In keeping with the ERAS protocol, on the day of surgery, the patients received fluids and meals if no post-operative nausea and vomiting (PONV) occurred and were rehabilitated.
The study was approved by the institutional review board (nr 1072.6120.11.2020). Following their giving oral and written consent to participate in the investigation, all the patients included in the study and subjected to the analysis were randomized into two groups: the study group and the controls using the double blind method. The study group (M) received methylprednisolone at the intravenous dose of $125 \mathrm{mg}$ as "preemptive" analgesia, and the controls $(\mathrm{K})$ saline solution as placebo. The statistical analysis included demographic dates, general condition in the ASA (American Society of Anesthesiology), POSSUM (Physiologic and Operative Severity Score for the enUmeration of Mortality and Morbidity), total dose of analgesic medications administered parenterally calculated for $1 \mathrm{~kg}$ of body mass in response to value of VAS/NRS at rest on day zero, time of administration of the first dose, and duration of fascia iliaca compartment blockade. On the day of surgery and on subsequent days, determinations were made for glycemia and inflammatory markers: CRP and leukocytosis levels.

The statistical analysis was performed using the Student $T$ test for independent groups employing the Cochran-Cox modification; the resultant statistical significance was $p<0.05$ employing the PQStat v 1.6.8 software.

\section{Results}

The analyzed groups were comparable as to the number of subjects: $\mathrm{M}$ group (methylprednisolone) - 39; K group (placebo) - 38 patients. There were no intergroup differences in the mean age, post-operative duration of hospitalization, duration of the procedure, intraoperative blood loss, and life parameters on the day of surgery. The groups differed in their peri-operative risk value as measured by the ASA and POSSUM scale (Tables 1 and 2).

In the post-operative period, the analysis included in the two groups: among inflammatory markers the leukocytosis, blood CRP levels on day zero, one, two and three post-operatively, and CRP level in the surgical wound drainage on day 0 ; glycemia levels on consecutive post-operative days; doses of analgesic medications administered on the day 0 ; and the duration of peripheral nerve block that was tantamount to the time of administration of the first analgesic agent dose (Table 3, Fig. 1 and Fig. 2).

The duration of fascia iliaca compartment blockade in the group $\mathrm{M}$ was significantly longer-only 8 patients $(20.51 \%)$ received oxycodone hydrochloride, in the group K 36 subjects $(94.73 \%)$ in view $\geq 4$ VAS/NRS pain level at rest (Fig. 2). 
Table 1 General data describing the analyzed elderly patients (over 65 years old) divided into the study group (M) and the controls (K)

\begin{tabular}{|c|c|c|c|}
\hline Data & Group (M) & Group (K) & $\begin{array}{l}p \\
\text { value }\end{array}$ \\
\hline$n$ & 39 & 38 & \\
\hline Age (years) & $72.66 \pm 6.92$ & $72.71 \pm 5.93$ & 0.97 \\
\hline $\begin{array}{l}\text { Mean duration of postoperative hospitalization } \\
\text { (days) }\end{array}$ & $4.89 \pm 2.64$ & $5.47 \pm 2.82$ & 0.35 \\
\hline ASA* & $\begin{array}{l}\text { II- } 76.93 \% ; \text { III- } \\
23.07 \%\end{array}$ & $\begin{array}{l}\mathrm{II}-42.1 \% ; \mathrm{III}- \\
57.9 \%\end{array}$ & \\
\hline Operative $\mathrm{MAP}^{\wedge}(\mathrm{mmHg})$ & $93.82 \pm 18.97$ & $93.62 \pm 16.48$ & 0.988 \\
\hline Operative heart rate $(\mathrm{x} / \mathrm{min})$ & $69.42 \pm 16.65$ & $73.75 \pm 17.23$ & 0.192 \\
\hline Post-operative $\mathrm{MAP}^{\wedge}(\mathrm{mmHg})$ & $93.04 \pm 9.27$ & $94.75 \pm 14.67$ & 0.947 \\
\hline Post-operative heart rate $(\mathrm{x} / \mathrm{min})$ & $71.84 \pm 6.73$ & $75.0 \pm 11.03$ & 0.238 \\
\hline Post-operative Sp02 (\%) & $98.4 \pm 0.89$ & $98.05 \pm 12.93$ & 0.974 \\
\hline
\end{tabular}

*American Society of Anesthesiologists Score

$\wedge^{\wedge}$ Mean arterial pressure

\section{Discussion}

The ERAS protocol with satisfactory multimodal analgesia is becoming a standard following the major orthopaedic procedures, shortens the post-operative time of hospitalization, and also makes it possible to promptly mobilize and effectively rehabilitate patients on the day of operation. Short hospitalization decreases the risk of infectious complications evoked by hospital bacterial strains $[2,11$, $12,15,18,19,21,22]$, as well as thrombotic, circulatory, and respiratory complications. Reports are published that describe replacement of major joints performed as "same day" procedures $[9,10,13]$.
In the present material, the mean post-operative hospitalization time was 4.89 days (2-17 days) in the study group and 5.47 days (2-19 days) in the controls $(p=0.35$, Table 1$)$. Prolonged hospitalization time involved one patient in each group, at the age 91 and 94 years with the difficulties in rehabilitation due to delirium. Significantly shorter time of the postoperative hospitalization following arthroplasty after entering the ERAS procedure presents a meta-analysis by Pamilo et al. (10) from Orthopedic Wards Finland - three days in the period of 2012-2013 vs. five days 2009-2010; by Memtsoudis et al. from 550 Europe's and United States's hospitals - three days in the period of 2006-2014; and by Farley et al. - 4.06 days before 2002 and 2.97 days in years 2012-2014 [10, 15, 23].
Table 2 Distribution of comorbidities and anaesthesia types in the analyzed patients above 65 years of age divided into the study group (M) and the controls $(\mathrm{K})$

\begin{tabular}{|c|c|c|c|c|c|}
\hline \multirow[t]{2}{*}{ Data } & \multicolumn{2}{|l|}{ Group M } & \multicolumn{2}{|l|}{ Group K } & \multirow[t]{2}{*}{$p$ value } \\
\hline & $n$ & $\%$ & $N$ & $\%$ & \\
\hline$n$ & 39 & 100 & 38 & 100 & \\
\hline Hypertension arterial & 39 & 100 & 38 & 100 & \\
\hline Atrial fibrillation, arrhythmia supraventricular & 6 & & 9 & & \\
\hline IHD, myocardial infarction in anamnesis & 5 & & 8 & & \\
\hline COPD grade III & 2 & & 5 & & \\
\hline TIA in anamnesis & 0 & 0 & 1 & & \\
\hline Circulatory failure chronic & 5 & & 9 & & \\
\hline Regional anesthesia & 39 & 100 & 38 & 100 & \\
\hline Intercompartmental nerve block analgesia & 39 & 100 & 38 & 100 & \\
\hline $\mathrm{ASA}^{\wedge} \mathrm{III}$ & 9 & 23.07 & 22 & 57.9 & 0.001537 \\
\hline POSSUM* ${ }^{*}$ physiological (points) & $17.30 \pm 3.88$ & & $20.00 \pm 3.99$ & & 0.0036 \\
\hline POSSUM* morbidity $(\%)$ & $24.57 \pm 12.50$ & & $33.17 \pm 15.49$ & & 0.0089 \\
\hline POSSUM* mortality (\%) & $1.53 \pm 1.56$ & & $2.15 \pm 1.63$ & & 0.09 \\
\hline
\end{tabular}

IHD ischemic heart disease, COPD chronic obstructive pulmonary disease, TIA transient ischemic attack

${ }^{\wedge}$ American Society of Anesthesiology Score,

*Physiological and Operative Severity Score for the enumeration of Morbidity and Mortality 
Table 3 Leukocytosis, C-reactive protein (CRP), and glucose levels in the analyzed patients aged above 65 years old divided into the study $(\mathrm{M})$ and control $(\mathrm{K})$ groups

\begin{tabular}{llllll}
\hline Data & Group $(\mathrm{M})$ & Group $(\mathrm{K})$ & OR & $-95 \mathrm{CI}$ & $p$ value \\
\hline$n$ & 39 & 38 & & & \\
Initial leukocytosis $\left(\times 10^{3} / \mu \mathrm{L}\right)$ & $7.58 \pm 2.5$ & $7.70 \pm 1.91$ & -0.12 & $-1.04 / 0.80$ & 0.80 \\
Leukocytosis on day zero & $12.11 \pm 3.25$ & $10.84 \pm 2.18$ & 1.27 & $0.013 / 2.53$ & 0.0477 \\
$\quad\left(\times 10^{3} / \mu \mathrm{L}\right)$ & & & & \\
Leukocytosis on day 1 $\left(\times 10^{3} / \mu \mathrm{L}\right)$ & $12.99 \pm 3.64$ & $12.02 \pm 2.26$ & 0.97 & $-0.40 / 2.35$ & 0.163 \\
Leukocytosis on day 2 $\left(\times 10^{3} / \mu \mathrm{L}\right)$ & $10.39 \pm 2.81$ & $11.84 \pm 2.51$ & -1.45 & $-2.67 /-0.24$ & $<0.0193$ \\
Leukocytosis on day 3 $\left(\times 10^{3} / \mu \mathrm{L}\right)$ & $8.94 \pm 2.04$ & $11.59 \pm 1.68$ & -2.66 & $-3.52 /-1.80$ & $<0.000001$ \\
Initial CRP $(\mathrm{mg} / \mathrm{L})$ & $2.77 \pm 1.55$ & $2.97 \pm 1.60$ & -0.19 & $-0.92 / 0.53$ & 0.5888 \\
CRP on day zero $(\mathrm{mg} / \mathrm{L})$ & $19.34 \pm 23.6$ & $41.91 \pm 22.69$ & -22.58 & $-33.09 /-12.06$ & 0.000056 \\
CRP on day 1 $(\mathrm{mg} / \mathrm{L})$ & $46.67 \pm 25.71$ & $102.19 \pm 34.1$ & -55.52 & $-69.28 /-41.76$ & $<0.000001$ \\
CRP on day 2 $(\mathrm{mg} / \mathrm{L})$ & $72.61 \pm 46.87$ & $144.40 \pm 54.39$ & -71.79 & $-94.88 /-48.70$ & $<0.000001$ \\
CRP on day 3 $(\mathrm{mg} / \mathrm{L})$ & $73.11 \pm 43.96$ & $140.75 \pm 56.78$ & -67.65 & $-90.88 /-44.41$ & $<0.000001$ \\
CRP drain $(\mathrm{mg} / \mathrm{L})$ & $6.24 \pm 8.48$ & $9.73 \pm 14.70$ & -8.98 & $-8.98 / 2.00$ & 0.20 \\
Initial glucose $(\mathrm{mmol} / \mathrm{L})$ & $5.60 \pm 0.81$ & $5.92 \pm 0.74$ & -0.32 & $-0.68 / 0.04$ & 0.084 \\
Glucose on day zero $(\mathrm{mmol} / \mathrm{L})$ & $6.80 \pm 0.99$ & $6.85 \pm 0.85$ & -0.05 & $-0.47 / 0.36$ & 0.796 \\
Glucose on day 1 $(\mathrm{mmol} / \mathrm{L})$ & $6.27 \pm 0.97$ & $6.60 \pm 0.78$ & -0.33 & $-0.73 / 0.07$ & 0.104 \\
Glucose on day 2 $(\mathrm{mmol} / \mathrm{L})$ & $5.78 \pm 0.81$ & $5.85 \pm 0.69$ & -0.065 & $-0.42 /-0.28$ & 0.706 \\
Glucose on day 3 $(\mathrm{mmol} / \mathrm{L})$ & $5.92 \pm 0.57$ & $6.10 \pm 0.56$ & -0.18 & $-0.44 / 0.07$ & 0.158 \\
\hline
\end{tabular}

$C R P$ C-reactive protein, $O R$ odds ratio, $C I$ confidence interval
Osteoarthritis of the hip joint has developed over many years, restricts physical activity, and affects patients more in their sixth - seventh decade of life. According to Ghironzi et al., the elderly age is the age when the progressive physiological decrease of the functional reserve occurs, leading to increasing incidence of diseases, mortality, and a decreased reproduction rate. Hence, the group of individuals from 85 years of life is at present more frequently recognized as the elderly age group [24, 25]. After 65 years of age, involution processes become significantly intensified; the 65 th year of life marks the beginning of the subject's so-called elderly patients $[12,13,24,25]$. The analyzed material represents the patients above 65 years. The initial condition of the patients differed in the two analyzed groups using the ASA scale and also differed in their post-operative condition, in the risk of possible comorbidities development by POSSUM physiological, morbidity, nevertheless were comparable with respect to the risk of possible post-operative death by POSSUM mortality (Table 2). In spite of differences in the severity of comorbidities, no significant post-operative complications were noted in either of the groups. One patient in each group, aged 91 and 94, developed transient post-operative delirium persisting for 2 and 3 days. No mortality was noted in the analyzed material. Farley et al. analyzed, among others, the influence of the comorbidities, abnormalities in laboratory values (high creatinine, glucose, low haemoglobin), opioid use, and hypotensive events in post-operative first day on the length of postoperative hospitalization in 1278 patients who underwent elective THA in an American hospitals in period 20122014. The average age of the analyzed patients was 62.3 years (SD 10.7). Length post-operative stay $\geq 3$ days in those cases was noted [15].

Lindberg-Larsen et al. analyzed effects of methylprednisolone administered preoperatively on the stability circulatory parameters in the time rehabilitation on the day of surgery THA in the University Orthopedic Hospital in Copenhagen. Although no significant difference was in the circulatory parameters during mobilization at day zero, as many as $40 \%$ of the control group subjects interrupted verticalization due to discomfort, as the effect of a higher dose of the opioid preparation, a higher CRP value in the group of patients [22].

The present authors demonstrated that the behaviour of the circulatory system parameters was maintained without any significant differences between the two groups, despite the early rehabilitation (Table 1) on the first post-operative day.

Meta-analyses based on studies employing methylprednisolone and placebo present a significant difference in pain assessment using the VAS scale in first 48 hours postoperatively and opioid agents administered parenterally per $1 \mathrm{~kg}$ of body mass [2, 4, 6, 18, 20, 21, 26-28]. Also confirmed by the present study (Figs. 1 and 2) were the differences in the experienced pain as based on the VAS/NRS scale in the M group and the $\mathrm{K}$ group measured on day 0 (Fig. 1) and, consequently, the statistical difference between the two groups in the dose of parenterally administered opioid preparations (oxycodone hydrochloride) expressed as $\mathrm{mg} / \mathrm{kg}$ of body weight given on first 24 hours post-operatively, but in the global dose of other analgesic preparations (metamizole, paracetamol), no significant difference was observed between the two groups (Fig. 2).

Similarly, as in increasingly more numerous reports published last year and currently, the present material confirmed that a single dose of methylprednisolone did not significantly affect local and generalized inflammation. In the literature on the subject, such parameters were evaluated as CRP levels, but also the level of endogenous anti-inflammatory protein pentraxin-3, markers of vascular endothelial dysfunction that initiates inflammation: syndecan-1, thrombomodulin, sE-Selectin or vascular 
Fig. 1 VAS/NRS values at rest presented as scores at $6,12,18$, and $24 \mathrm{~h}$ post-operatively in the analyzed patients above 65 years of age divided into the study group (M) and the controls (K)
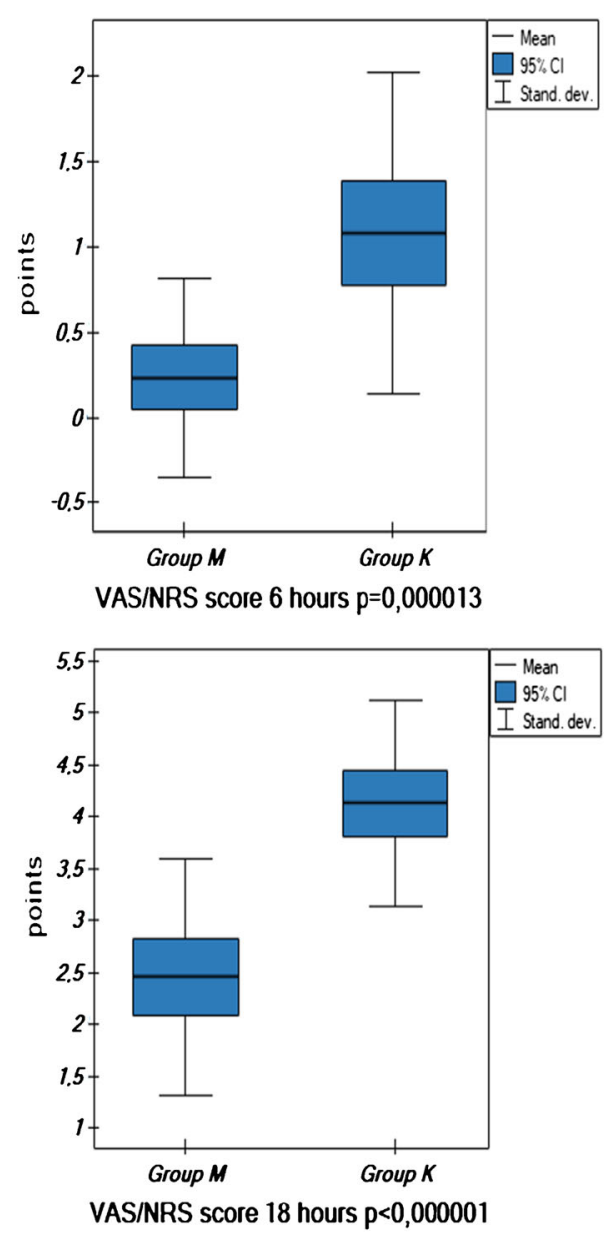
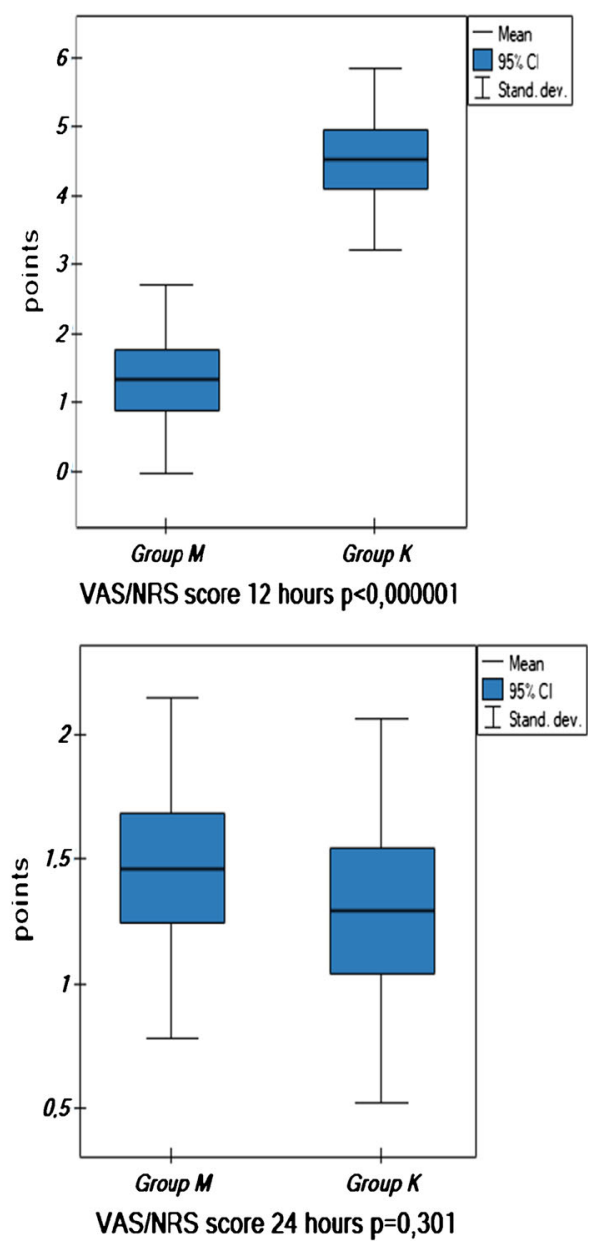

endothelial growth factor (VEGF), interleukin-6, tumor necrosis factor-alfa [16, 17, 29]. Although in 2017 Lindberg-Larsen et al. demonstrated a significantly higher level of pentraxin-3 in the group of patients who received a single dose of methylprednisolone in the first 24 post-operative hours, they documented the absence of local and generalized inflammation development [16]. In another paper, the same group of investigators evaluated the levels of markers of vascular endothelium dysfunction following administration of methylprednisolone vs. placebo after knee arthroplasty. Analyzing the decreasing levels of syndecan1 and sE-Selectin, thrombomodulin and VEGF, they showed a significantly lower vascular endothelial dysfunction level in the first 24 hours post-operatively in the group of patients administered a single dose of methylprednisolone as compared with the placebo group [17]. Tilinca et al. (2018) analyzed the level of inflammatory markers (interleukin-6, TNF- $\alpha$ ) in peri-operative period THA/TKA in the two groups of patients: obese vs. normal body mass index; significant increases in levels of both parameters in the groups of obese subjects [29] were observed. The available literature does not confirm development of local and generalized inflammation [7, 15, 21, 26, 27, 16-18]. Numerous reports point to the fact that the level of CRP does not demonstrate significant differences between the group that received methylprednisolone and the group in which the medication was not employed. In the present material, the analysis focused on such selected inflammatory markers as leukocytosis, and blood and wound drainage fluid CRP levels. The leukocytosis level was significantly higher on day zero in the study group, but the value dropped markedly as early as on days two and three post-operatively (Table 3); in turn, the CRP level was significantly lower in the group "methylprednisolone" as compared with the placebo group. The CRP value in the drainage fluid did not differ between the two groups (Table 3).

As it was demonstrated in the present material, a single dose of methylprednisolone did not significantly affect glycemia fluctuations (Table 3). Similarly, as indicated by data from the literature, the present authors noted in the two groups a transient increase in glycemia, without significant increase in the first 24-48 hours post-operatively [15, 30].

Degenerative changes of peripheral neurons occurring in the process of progressive aging lead to prolonged signal transduction $[8,24,25]$. In consequence, the duration of the effect of peripheral nerve block is prolonged; the intercompartmental peripheral nerve block in the presented material in the group $\mathrm{M}$ was 
Fig. 2 Doses of analgesic medications and duration of postoperative analgesia not requiring analgesics administration on the day of surgery in the analyzed patients above 65 years of age divided into the study group (M) and the controls $(\mathrm{K})$
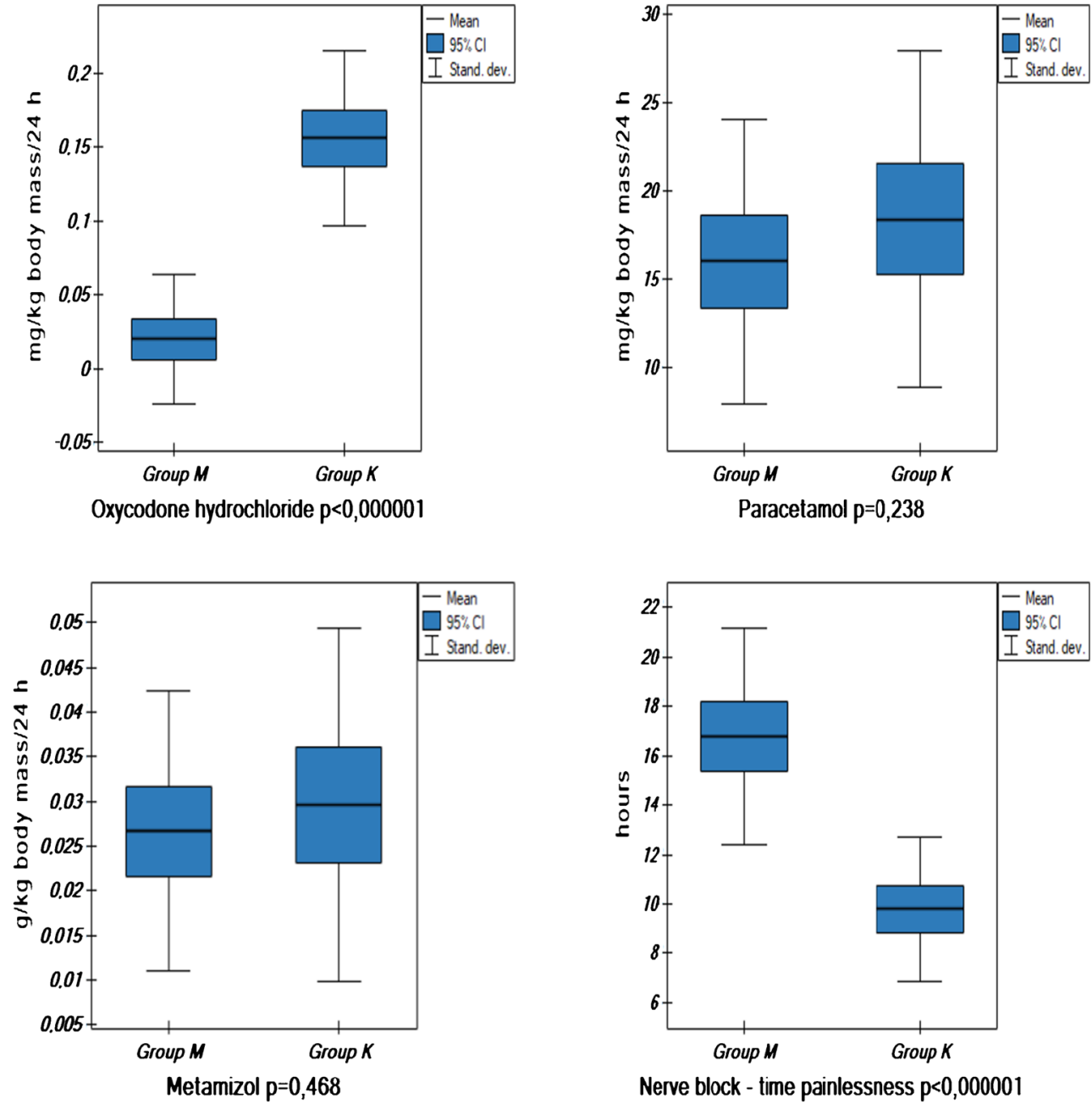

almost twice longer contrary to the group $\mathrm{K}$. The material included patients above 65 years of age, whose reaction to local anaesthesia drugs is similar; thus, the difference is from one variable only, i.e., methylprednisolone administration (Fig. 2).

The recently published reports of Kehlet et al. [12, 15, 31, 39,40 ] point to this safe aspect of administering a single dose of methylprednisolone that is associated with a quantifiable beneficiary analgesic effect in patients after extensive orthopaedic procedures, with limited post-operative complications $[4,6,7,10,15,18,22,27,31-33]$.

In summary, the use of a single dose of methylprednisolone fits in multimodal analgesia in the group of patients above 65 years after surgery unilateral THA: (1) noticeably decreases the level of post-operative pain assessed using the VAS/NRS scales at rest in all time intervals on the day of surgery, and decreases the dose of opioid analgesic medications (oxycodone hydrochloride); (2) no effect has been demonstrated and development of infection symptoms, have noted significantly lower levels of inflammatory markers, CRP levels on all the analyzed post-operative days, leukocytosis level on days two and three post-operatively; (3) no significant difference in glycemia level has been demonstrated; (4) supports the stability of the circulatory system and no adverse effects that would delay patient mobilization and early rehabilitation as per the ERAS protocol.

\section{Compliance with ethical standards}

Conflict of interest The authors declare that they have no conflict of interest.

Ethical approval This trial was approved by the institutional review board (Bioethics Committee of the Jagiellonian University, nr 1072.6120.11.2020).

Informed consent Informed consent was obtained from all individual participants included in the study.

Open Access This article is licensed under a Creative Commons Attribution 4.0 International License, which permits use, sharing, adaptation, distribution and reproduction in any medium or format, as long as you give appropriate credit to the original author(s) and the source, provide a link to the Creative Commons licence, and indicate if changes were 
made. The images or other third party material in this article are included in the article's Creative Commons licence, unless indicated otherwise in a credit line to the material. If material is not included in the article's Creative Commons licence and your intended use is not permitted by statutory regulation or exceeds the permitted use, you will need to obtain permission directly from the copyright holder. To view a copy of this licence, visit http://creativecommons.org/licenses/by/4.0/.

\section{References}

1. Lee B, Schug SA, Joshi GP, Kehlet H (2018) Procedure-specific Pain Management (PROSPECT) - an update. Best Pract Res Clin Anaesthesiol 32:101-111

2. Shen S, Gao Z, Liu J (2018) The efficacy and safety of methylprednisolone for pain control after knee arthroplasty: a meta-analysis of randomized controlled trials. Int J Surg 57:91-100

3. Li X, Xu G, Xie W, Ma S (2018) The efficacy and safety of dexamethasone for pain management after total knee arthroplasty: a systemic review and meta-analysis. Int J Surg 53:65-71

4. Luna IE, Kehlet H, Petersen MA, Aasvang EK (2017) Clinical, nociceptive and psychological profiling to predict acute pain after total knee arthroplasty. Acta Anaesthesiol Scand 61:676-687

5. Geisler A, Dahl JB, Karlsen AP, Persson E, Mathiesen O (2017) Low degree od satisfactory individual pain relief in post-operative pain trials. Acta Anaestesiol Scand 61:83-90

6. Karlsen APH, Dahl JB, Mathiesen O (2018) Evolution of bias and sample size in postoperative pain management trials after hip and knee arthroplasty. Acta Anaesthesiol Scand 62:666-676

7. Lunn TH, Kehlet H (2013) Perioperative glucocorticoids in hip and knee surgery - benefit vs. harm? A review of randomized clinical trials. Acta Anaesthesiol Scand 57:823-834

8. Purcell RL, Nappo KE, Griffin DW, McCabe M, Anderson T, Kent M (2018) Fascia iliaca blockade with the addition of liposomal bupivacaine vc plain bupivacaine for perioperative pain management following hip arthroscopy. Knee Surg Sports Traumatol Arthrosc 26:2536-2541

9. Vehmeijer S, Husted H, Kehlet H (2018) Outpatient total hip and knee arthroplasty. Fact and challenges. Acta Orthop. 89:141-144

10. Pamilo K, Torkki P, Peltola M, Pesola M, Remes V, Paloneva J (2018) Fast-track for total knee replacement reduces use of institutional care without compromising quality. Acta Orthop 89:184-189

11. Jorgensen CC, Kehlet H (2017) Time course and reasons for 90-day mortality in fast-track hip and knee arthroplasty. Acta Anaesthesiol Scand 61:436-444

12. Krenk L, Rasmussen LS, Hansen TB, Bogø S, Søballe K, Kehlet H (2012) Delirium after fast-track hip and knee arthroplasty. Br J Anaesth 108:607-611

13. Petersen PB, Jorgensen CC, Kehlet H (2017) Delirium after fasttrack hip and knee arthroplasty - a cohort study of 6331 elderly patients. Acta Anaesthesiol Scand 61:767-772

14. Dong Q, Zhang Y, Sun X, Hu F (2018) The effectiveness and safety of aminocaproic acid for reducing blood loss in total knee and hip arthroplasty: a metaanalysis. Int J Surg 52:156-163

15. Farley K, Anastasio A, Premkumar A, Boden SD, Gottschalk MB, Bradbury TL (2019) The influence of modifiable, postoperative patient variables on the lenght of stay after total hip arthroplasty. J Arthroplasty 34:901-906

16. Lindberg-Larsen V, Kehlet H, Pilely K, Bagger J, Rovsing ML, Garred P (2017) Preoperative methylprednisolone increases plasma Pentraxin 3 early after total knee arthroplasty: a randomized, double-blind, placebo-controlled trail. Clin Exp Immunol 191:356-362
17. Lindberg-Larsen V, Ostrowski SR, Lindberg-Larsen M, Rovsing ML, Johansson PI, Kehlet H (2017) The effect of preoperative methylprednisolone on early endothelial damage after knee arthroplasty: a randomized, double-blind, placebo-controlled trial. Anesthesia. 72:1217-1224

18. Jorgensen CC, Pitter FT, Kehlet H (2017) Safety aspects of preoperative high-dose glucocorticoid in primary total knee replacement. B J Anaesth 119:267-275

19. Kehlet H (2013) Fast-track hip and knee arthroplasty. Lancet. 381: $1600-1602$

20. Mohammad H, Hamilton TW, Strickland L, Trivella M, Murray D, Pendit H (2018) Perioperative adjuvant corticosteroids for postoperative analgesia in knee arthroplasty. Acta Orthop 89:71-76

21. Lunn TH, Anderson LO, Kristensen BB, Husted H, Gaarn-Larsen L, Bandholm T et al (2013) Effect of high-dose preoperative methylprednisolone on recovery after total hip arthroplasty: a randomized, double-blind, placebo-controlled trial. B J Anaesth 110:66-73

22. Lindberg-Larsen V, Petersen PB, Jans O, Beck T, Kehlet H (2018) Effect of pre-operative methylprednisolone on orthstatic hypotension during early mobilization after total hip. Acta Anaesthesiol Scand 62:882-892

23. Memtsoudis S, Poeran J, Zubizarreta N, Olson A, Cozowicz C, Mörwald EE et al (2018) Do hospitals performing frequent neuraxial anesthesia for hip and knee replacements have better outcomes? Anesthesiology. 129:428-439

24. Reves JG, Barnet SR, Mc Swain JR, Rooke GA (2018) Geriatric anesthesiology. Springer

25. Ghironzi G, Capeta JC, Cortes F, Bettelli G (2018) Aging and agerelated functional changes. Perioperative Care of the Elderly. Cambridge Medicine

26. Kehlet H (2007) Glucocorticoidss for peri-operative analgesia: how far are from general recommendations? Acta Anaesthesiol Scand 51:113-1135

27. Kehlet H, Lindberg-Larsen V (2018) High-dose glucocorticoid before hip and knee arthroplasty: to use or not to use - that's the question. Acta Orthop 89(5):477-479

28. Bautista M, Muskus M, Llinas A, Bonilla G, Guerrero C, Moyano J (2018) Peri-articular injection of an analgesic mixture in primary total hip arthroplasty: an effective strategy for pain control during the first post-operative day. Int Orthop 42:1803-1810

29. Tilinca MC, Zazgyva A, Pop TS (2019) Differences in perioperative serum inflammatory markers between normoponderal and obese patients undergoing large joint replacement for osteoarthritis - a descriptive study. Int Orthop 43:1735-1740

30. Varady N, Schwab P, Jones T, Collins JE, Fitz W, Chen AF (2019) Optimal timing of glucose measurements after total joint arthroplasty. J Arthroplasthy 34:S152-S158

31. Zhao H, Xiang M, Xia Y, Shi X, Pei FX, Kang P (2018) Efficacy of oral tranxemic acid on blood loss in primary total hip arthroplasty using a direct anterior approach: a prospective randomized controlled trial. Int Orthop 42:2535-2542

32. Cao G, Huang Q, Huang Z, Zhang S, Luo Z, Lei Y et al (2019) The efficacy and safety of multiple-dose oral tranexamic acid on blood loss following total hip arthroplasty: a randomized controlled trial. Int Orthop 43:299-305

33. Scardino M, Martorelli F, D'Amato T, Fenocchio G, Simili V, Grappiolo $G$ et al (2019) Use of fibrin sealent within a bloodsaving protocol in patients undergoing revision hip arthroplasty: effects on postoperative blood transfusion and healthcare-related cost analysis. Int Orthop 43:2707-2714

Publisher's note Springer Nature remains neutral with regard to jurisdictional claims in published maps and institutional affiliations. 